\title{
BMJ Open Prevalence of and rationale for antimicrobial prescription during ambulatory care visits in Japan: a prospective, multicentre, cross- sectional study
}

Junpei Komagamine (1), ${ }^{1}$ Masaki Kobayashi, ${ }^{2}$ Takahiro Mori ${ }^{3}$

To cite: Komagamine J, Kobayashi M, Mori T. Prevalence of and rationale for antimicrobial prescription during ambulatory care visits in Japan: a prospective, multicentre, cross-sectional study. BMJ Open 2020;10:e039329. doi:10.1136/ bmjopen-2020-039329

- Prepublication history for this paper is available online. To view these files, please visit the journal online (http://dx.doi org/10.1136/bmjopen-2020039329).

Received 11 April 2020 Revised 27 July 2020 Accepted 28 July 2020

Check for updates

(C) Author(s) (or their employer(s)) 2020. Re-use permitted under CC BY-NC. No commercial re-use. See rights and permissions. Published by BMJ.

${ }^{1}$ Internal Medicine, National Hospital Organization Tochigi Medical Center, Utsunomiya, Tochigi, Japan

${ }^{2}$ Geriatrics and Gerontology, National Hospital Organization Tokyo Medical Center, Meguroku, Tokyo, Japan

${ }^{3}$ Internal Medicine, National Hospital Organization Nagasaki Medical Center, Omura, Nagasaki, Japan

Correspondence to Dr Junpei Komagamine; junpei0919@yahoo.co.jp

\section{ABSTRACT}

Objective To determine the rate of outpatient antimicrobial use and the rationale for antimicrobial prescription.

Design A prospective, multicentre, cross-sectional study. Setting Ambulatory care settings at community general hospitals.

Participants A total of 1972 consecutive ambulatory visits by 1952 patients were included from 2 February 2020 to 13 February 2020. Visits resulting in hospital admission and regularly scheduled visits were excluded. Main outcome measures The primary outcome was the proportion of ambulatory visits resulting in antimicrobial drug prescriptions. The secondary outcomes were the reasons for antimicrobial drug prescription and the proportion of unnecessary antimicrobial prescriptions among all antimicrobial drugs used for treatment. Results The mean patient age was 53.8 (SD 25.8) years old, and the proportion of women was $52.6 \%$. A total of 162 antimicrobial drugs were prescribed in 153 $(7.8 \%)$ visits. The most common antimicrobial drugs were penicillins ( $n=48,29.6 \%)$, followed by third-generation cephalosporins $(n=35,21.6 \%)$ and quinolones $(n=20$, $12.4 \%)$. Among all the antimicrobial drugs prescribed, $125(77.2 \%), 18(11.1 \%)$ and $11(6.8 \%)$ were used for infection treatment, wound prophylaxis and surgical prophylaxis, respectively. Of the 125 antimicrobial drugs used for infection treatment, $60(48.0 \%)$ were judged to be unnecessary.

Conclusions One in every 13 ambulatory visits resulted in antimicrobial use in Japan. Three-fourths of the prescribed antimicrobial drugs were used for infection treatment, but approximately half of those drugs may have been unnecessary. Further efforts to reduce unnecessary antimicrobial drug use are needed.

Trial registration number UMIN000039360.

\section{INTRODUCTION}

Antimicrobial-resistant bacterial infections have been increasing ${ }^{1}$ and have become a global concern. Infections caused by antimicrobial-resistant bacteria are associated with an increased risk of mortality and
Strengths and limitations of this study

- This is the first multicentre study in Japan to investigate the rationale for antimicrobial use in an outpatient setting.

- Diagnosis and reasons for antimicrobial drug use were determined based on chart reviews rather than diagnostic codes.

- The inclusion of only three hospitals limited the generalisability of our findings to other hospitals.

- The rationale for antimicrobial drug use might be inaccurate because the physicians who prescribed the antimicrobial drugs were not contacted.

increased economic burdens. ${ }^{2}{ }^{3}$ One of the main drivers for the increase in antimicrobialresistant bacterial infections is antimicrobial drug use. ${ }^{4}$ In 2015, the WHO launched the global action plan to combat antimicrobialresistant bacterial infections, ${ }^{5}$ and a national action plan was launched by the government of Japan in $2016 .^{6}$

Given that most antimicrobial drugs are prescribed in ambulatory settings, ${ }^{7}$ reducing unnecessary antimicrobial drug prescriptions in ambulatory settings is essential to reduce the rate of antimicrobial-resistant bacterial infections. Nonetheless, inappropriate antimicrobial drug use is common. Recent studies have reported that $20 \%-40 \%$ of outpatient antimicrobial drug prescriptions are unnecessary. ${ }^{8-10}$ However, few studies analysing recent data after the launch of the WHO's action plan have been conducted to investigate the appropriateness of outpatient antimicrobial drug use. Therefore, more recent information on outpatient antimicrobial drug use is needed. Furthermore, recent studies ${ }^{8-10}$ have used diagnostic codes to identify infectious diseases that are being treated with antimicrobial drugs. Given that the 
accuracy of physicians' diagnoses ${ }^{11}$ or diagnostic codes ${ }^{12}$ for infectious diseases have been reported to be limited in past studies, the methods to assess the appropriateness of antimicrobial drug use by using diagnostic codes may be suboptimal. In addition, antimicrobial drug use for prophylaxis and non-infectious reasons was not considered in most studies. ${ }^{8-10}$ Given that inappropriate antimicrobial drug use for prophylaxis is common in in-hospital settings, ${ }^{13}$ it is important to determine the proportion of prophylactic use of antimicrobial drugs in an ambulatory setting. Thus, a prospective multicentre cross-sectional study was conducted to investigate the rationale and appropriateness of outpatient antimicrobial drug use by using medical chart reviews.

\section{METHODS}

\section{Study setting and design}

Japan has a universal health insurance system that was introduced in 1961. Most of the residents in Japan are enrolled in either the Employees' Health Insurance, National Health Insurance, or Later Elders' Health Insurance. Under these health insurance systems, the copayment rate for patients varies from $10 \%$ to $30 \%$ depending on several factors, such as the enrollees' income and the combination of other insurance plans. The Japanese healthcare system has a unique feature that people can choose any healthcare facility regardless of the severity of their disease. ${ }^{14}$ For example, patients with common cold symptoms can freely visit secondary or tertiary care hospitals without a referral from a primary care physician. Therefore, primary care physicians in clinics do not strictly serve as gatekeepers to coordinate patient care, and physicians in hospitals often provide primary care in Japan. Hospital-based outpatient care accounts for approximately $30 \%$ of all outpatient visits for medical reasons in Japan. ${ }^{15}$

A prospective, cross-sectional study was conducted at the National Hospital Organization (NHO) Tokyo Medical Center (a 740-bed community care hospital) from 2 February 2020 to 5 February 2020, the NHO Nagasaki Medical Center (a 643-bed community care hospital) from 2 February 2020 to 13 February 2020 and the NHO Tochigi Medical Center (a 350-bed community care hospital) from 2 February 2020 to 12 February 2020. These are community general hospitals that provide primary and secondary care for different regions of Japan. The mean numbers of outpatient visits per day in each hospital were approximately 1500 for NHO Tokyo Medical Center, approximately 800 for NHO Nagasaki Medical Center and approximately 600 for NHO Tochigi Medical Center. These hospitals have antimicrobial stewardship teams to monitor and improve inpatient antimicrobial drug use. However, there were no antimicrobial stewardship interventions or guidelines for outpatient antimicrobial drug use at the time of the present survey in these hospitals.
The prevalence and appropriateness of antimicrobial drug use in ambulatory settings in Japan were determined by reviewing electronic medical records. This study was registered in the University Hospital Medical Information Network Clinical Registry on 1 February 2020.

\section{Inclusion and exclusion criteria}

All consecutive patients who visited any of the three hospitals during the study period were included. Visits that resulted in hospital admission were excluded. Visits for only annual health checks and scheduled visits were also excluded. If multiple unplanned visits for the same reason occurred during the study period, only the first visit was included. However, multiple unplanned or new visits for different reasons during the study period were evaluated separately.

\section{Data collection}

Physicians reviewed the electronic medical records and retrieved information on patients' age, sex, chief complaints, presence of fever, use of antimicrobial drugs, reasons for antimicrobial drug use and diagnosis. The presence of fever was defined as a temperature of $38.0^{\circ} \mathrm{C}$ or higher regardless of the measurement site. The name and duration of antimicrobial drugs used were recorded. Antimicrobial drugs were classified based on the WHO Anatomical Therapeutic Chemical classification. Based on a past study, ${ }^{16}$ the reasons for the use of each antimicrobial drug were initially recorded and classified into the following five categories: infection treatment, medical prophylaxis, surgical prophylaxis, a non-infectious reason, or unknown. However, during the survey, prophylaxis for wounds was added as an additional category because whether antimicrobial drug use for uninfected wounds should be classified into medical or surgical prophylaxis was uncertain. For information on diagnoses, physicians' diagnoses documented in medical charts were recorded. If there was no documentation of the diagnosis in the medical chart, we relied on the physician's assigned International Classification of Diseases and Related Health Problems, 10th Revision (ICD-10) diagnostic code.

Collection of these data was performed by one investigator per hospital. Then, the first author determined whether data were missing in the collected information from the three hospitals. If the data were missing, information on the missing data was recollected by the investigator in charge of the investigated hospital. Assessments of data accuracy by multiple investigators were not performed. Approximately 4 hours is needed to collect the data from 100 patients, although we did not investigate the exact time needed to complete the survey.

\section{Outcome measures}

The primary outcome was the proportion of ambulatory visits resulting in antimicrobial drug prescriptions. A visit was considered to result in prescription of antimicrobial drugs if a patient was prescribed any antimicrobial drug on the day of visit. Oral, parenteral, intramuscular and 
inhaled antimicrobial drugs were included, but topical antimicrobial drugs were excluded.

The secondary outcomes were the reasons for antimicrobial drug prescription and the proportion of unnecessary antimicrobial prescriptions for treatment considering all antimicrobial drugs. For the latter outcome, we first evaluated whether there was evidence for a physician's diagnosis of a target infectious disease because physicians' diagnoses ${ }^{11}$ or diagnostic codes ${ }^{12}$ are often inaccurate. Then, whether antimicrobial drugs were indicated for the target infectious disease was assessed by three investigators based on clinical guidelines. ${ }^{17}{ }^{18}$ Based on these assessments, antimicrobial drugs were judged to be unnecessary if there was insufficient evidence for a diagnosis or no indication of antimicrobial therapy for the target infectious disease. If a documented reason existed for antimicrobial drug use but the evidence available did not support the rationale for its use, the antimicrobial therapy was judged to be not indicated. Example cases in which antimicrobial drugs were judged to be unnecessary are shown in online supplementary table $\mathrm{S} 1$. These assessments were performed by one investigator per hospital.

\section{Statistical analysis}

The baseline characteristics of the study population were reported using descriptive statistics. The 95\% CIs were calculated for the primary and secondary outcomes. The Excel statistical software package V.2.11 (Bell Curve for Excel; Social Survey Research Information, Tokyo, Japan) was used for the statistical analyses.

\section{Patient and public involvement}

No patients were involved in determining the research question or outcome measures, nor were they involved in developing plans to design or implement the study. No patients were asked for advice during the interpretation or reporting of the results. There are no plans to disseminate the results of this research to the study participants or the relevant patient community.

\section{RESULTS}

During the study period, a total of 1972 consecutive ambulatory visits by 1952 patients were included (table 1 and online supplementary table S2). Of those, 367 visits $(18.7 \%)$ were emergency department visits. The mean patient age was 53.8 (SD 25.8) years old, and the proportion of women was $52.6 \%$. Patients reported any symptoms in 1305 visits $(66.2 \%)$ and reported fever in 129 visits $(6.5 \%)$. The most common infectious disease diagnosis was the common cold $(n=49,2.5 \%)$, followed by dental infections $(n=37,1.9 \%)$ and acute gastroenteritis $(\mathrm{n}=27,1.4 \%)$.

A total of 162 antimicrobial drugs were prescribed in $153(7.8 \%)$ visits (table 2 and online supplementary table S3). Antimicrobial drugs prescribed by internal medicine $(n=38,23.5 \%)$, urology $(n=22,13.6 \%)$, oral surgery $(n=19$, $11.7 \%)$ and paediatric $(\mathrm{n}=19,11.7 \%)$ units accounted for approximately $60 \%$ of all prescribed antimicrobial drugs. Among 261 visits by patients aged less than 18 years, 32 visits $(12.3 \%)$ resulted in the prescription of antimicrobial drugs, while antimicrobial drugs were prescribed in $54(6.1 \%)$ of 883 visits by patients aged more or 65 years. For respiratory tract infections, the rates of antimicrobial drug prescriptions for common cold $(n=49)$, acute pharyngitis $(n=21)$, acute bronchitis $(n=20)$, influenza $(n=16)$ and bacterial pneumonia $(\mathrm{n}=14)$ were $6.1 \%, 47.6 \%$, $45.0 \%, 68.8 \%$ and $85.7 \%$, respectively.

Of the 162 antimicrobial drugs, the most common antimicrobial drugs were penicillins $(n=48,29.6 \%)$, followed by third-generation cephalosporins $(\mathrm{n}=35,21.6 \%)$ and quinolones $(n=20,12.4 \%)$ (table 3$)$. Of all the antimicrobial drugs, $125(77.2 \%), 18(11.1 \%), 11(6.8 \%)$ and $4(2.5 \%)$ were used for infection treatment, wound prophylaxis, surgical prophylaxis and medical prophylaxis, respectively. Of the 125 antimicrobial drugs used for infection treatment, the most common target infectious disease was urinary tract infection (UTI) $(n=20$, $16.0 \%)$, followed by bacterial pneumonia $(n=13,10.4 \%)$, acute pharyngitis $(\mathrm{n}=11,8.8 \%)$, skin infections $(\mathrm{n}=11$, $8.8 \%)$, influenza $(\mathrm{n}=11,8.8 \%)$ and dental infections $(\mathrm{n}=10,8.0 \%)$ (table 4$)$. These six infectious diseases accounted for approximately $60 \%$ of all antimicrobial drugs prescribed for infection treatment. Of the 29 antimicrobial drugs used for wound or surgical prophylaxis, the mean duration of antimicrobial drug use was 2.9 days (SD 1.5). Among them, 16 antimicrobial drugs (55.2\%) were prescribed for more than 2 days.

Among the 125 target infectious diseases treated with antimicrobial for infection treatment, evidence for the diagnosis of 45 (36.0\%) diseases was judged to be insufficient (table 5). Evidence for the diagnosis was insufficient in $8(40.0 \%)$ and $3(23.1 \%)$ of the 20 UTI and 13 bacterial pneumonia cases treated by antimicrobial drugs, respectively. Of the 125 antimicrobial drugs used for infection treatment, $60(48.0 \%)$ were judged to be unnecessary. Among infectious diseases for which unnecessary antimicrobial drugs were prescribed, the most common infectious diseases were acute pharyngitis $(n=9,15.0 \%)$ and acute bronchitis $(n=9,15.0 \%)$, followed by UTI $(n=8$, $6.4 \%)$.

\section{DISCUSSION}

Prevalence of and rationale for antimicrobial drug prescription in the ambulatory care setting

The proportion of visits that resulted in the prescription of antimicrobial drugs in this study was $7.8 \%$, similar to that reported in past studies. ${ }^{812} 1920$ In the present study, approximately three-fifths of all prescribed antimicrobial drugs were used for infection treatment, while approximately one-fifth of those were used for surgical, wound or medical prophylaxis. Although few studies on the rationale of antimicrobial drug use in ambulatory settings have ever been conducted, one retrospective cross-sectional study $^{12}$ reported that $6.2 \%$ of antimicrobial drugs 
Table 1 Clinical characteristics of the 1972 ambulatory visits according to site*

\begin{tabular}{|c|c|c|c|c|}
\hline Characteristics & All $(n=1972)$ & Tokyo $(n=637)$ & Nagasaki $(n=608)$ & Tochigi $(n=727)$ \\
\hline Patient mean age, years (SD) & $53.9(25.8)$ & $57.0(22.3)$ & $49.6(27.3)$ & $54.6(27.0)$ \\
\hline Women & $1038(52.6)$ & $364(57.1)$ & $314(51.6)$ & $360(49.5)$ \\
\hline \multicolumn{5}{|l|}{ Department } \\
\hline Internal medicine & $683(34.6)$ & $258(40.5)$ & $234(38.5)$ & $191(26.3)$ \\
\hline Oral surgery & $139(7.0)$ & $29(4.6)$ & $0(0.0)$ & $110(15.1)$ \\
\hline Paediatrics & $135(6.8)$ & $7(1.1)$ & $68(11.2)$ & $60(8.3)$ \\
\hline Surgery & $129(6.5)$ & $42(6.6)$ & $48(7.9)$ & $39(5.4)$ \\
\hline Urology & $116(5.9)$ & $35(5.5)$ & $25(4.1)$ & $56(7.7)$ \\
\hline Direct visit with symptoms & 727 (36.9) & $180(28.3)$ & $165(27.1)$ & $382(52.5)$ \\
\hline Referral with symptoms & $578(29.3)$ & $250(39.3)$ & $207(34.1)$ & $121(16.6)$ \\
\hline Referral without symptoms & $571(29.0)$ & $172(27.0)$ & $236(38.8)$ & $163(22.4)$ \\
\hline Other reasons & $96(4.9)$ & $35(5.5)$ & $0(0.0)$ & $61(8.4)$ \\
\hline Presence of fever† & $129(6.5)$ & $27(4.2)$ & $48(7.9)$ & $54(7.4)$ \\
\hline \multicolumn{5}{|l|}{ Diagnosis } \\
\hline Common cold & $49(2.5)$ & $15(2.4)$ & $18(3.0)$ & $16(2.2)$ \\
\hline Traumatic wound & $39(2.0)$ & $8(1.3)$ & $17(2.8)$ & $14(1.9)$ \\
\hline Dental infection & $37(1.9)$ & $12(1.9)$ & $0(0.0)$ & $25(3.4)$ \\
\hline Influenza & $16(0.8)$ & $3(0.5)$ & $6(1.0)$ & $7(1.0)$ \\
\hline Rhinitis & $13(0.7)$ & $2(0.3)$ & $1(0.2)$ & $10(1.4)$ \\
\hline Bacterial pneumonia & $14(0.7)$ & $4(0.6)$ & $4(0.7)$ & $6(0.8)$ \\
\hline Skin infection & $12(0.6)$ & $2(0.3)$ & $1(0.2)$ & $9(1.2)$ \\
\hline Exacerbation of asthma & $10(0.5)$ & $4(0.6)$ & $3(0.5)$ & $3(0.4)$ \\
\hline Cough unspecified & $6(0.3)$ & $2(0.3)$ & $1(0.2)$ & $3(0.4)$ \\
\hline Burn & $6(0.3)$ & $1(0.2)$ & $1(0.2)$ & $4(0.6)$ \\
\hline Genital infections & $5(0.3)$ & $1(0.2)$ & $1(0.2)$ & $3(0.4)$ \\
\hline Exacerbation of COPD & $4(0.2)$ & $1(0.2)$ & $2(0.3)$ & $1(0.1)$ \\
\hline Acute sinusitis & $4(0.2)$ & $2(0.3)$ & $1(0.2)$ & $1(0.1)$ \\
\hline Otitis externa & $3(0.2)$ & $0(0.0)$ & $0(0.0)$ & $3(0.4)$ \\
\hline Non-suppurative otitis media & $3(0.2)$ & $1(0.2)$ & $2(0.3)$ & $0(0.0)$ \\
\hline Acute otitis media & $3(0.2)$ & $0(0.0)$ & $2(0.3)$ & $1(0.1)$ \\
\hline Acute prostatitis & $2(0.1)$ & $2(0.3)$ & $0(0.0)$ & $0(0.0)$ \\
\hline Acne & $2(0.1)$ & $0(0.0)$ & $1(0.2)$ & $1(0.1)$ \\
\hline Other infections & $53(2.7)$ & $19(3.0)$ & $17(2.8)$ & $17(2.3)$ \\
\hline
\end{tabular}

*Values are expressed as the number and the percentage of the total number unless otherwise stated.

†Defined as $38.0^{\circ} \mathrm{C}$ or higher regardless of measurement site.

COPD, chronic obstructive pulmonary disease.; 
Table 2 The proportion of visits that resulted in the prescription of antimicrobial drugs according to age, sex, setting and diagnosis* $^{*}$

\begin{tabular}{|c|c|c|c|c|c|c|c|c|}
\hline \multirow[b]{2}{*}{ Characteristics } & \multicolumn{2}{|c|}{ All (n=1972) } & \multicolumn{2}{|c|}{ Tokyo $(n=637)$} & \multicolumn{2}{|c|}{ Nagasaki ( $n=608)$} & \multicolumn{2}{|c|}{ Tochigi $(\mathrm{n}=727)$} \\
\hline & Total & $\begin{array}{l}\text { Visits with } \\
\text { antimicrobial } \\
\text { drugs }\end{array}$ & Total & $\begin{array}{l}\text { Visits with } \\
\text { antimicrobial } \\
\text { drugs }\end{array}$ & Total & $\begin{array}{l}\text { Visits with } \\
\text { antimicrobial } \\
\text { drugs }\end{array}$ & Total & $\begin{array}{l}\text { Visits with } \\
\text { antimicrobial } \\
\text { drugs }\end{array}$ \\
\hline All visits & 1972 & $153(7.8)$ & 637 & $42(6.6)$ & 608 & $31(5.1)$ & 727 & $80(11.0)$ \\
\hline \multicolumn{9}{|l|}{ Patient age (years) } \\
\hline $0-17$ & 261 & 32 (12.3) & 35 & $3(8.6)$ & 119 & $8(6.7)$ & 107 & $21(19.6)$ \\
\hline $18-64$ & 828 & $67(8.1)$ & 317 & $26(8.2)$ & 237 & $11(4.6)$ & 274 & $30(10.9)$ \\
\hline 65 or older & 883 & $54(6.1)$ & 285 & $13(4.6)$ & 252 & $12(4.8)$ & 346 & $29(8.4)$ \\
\hline Women & 1038 & $68(6.6)$ & 364 & $22(6.0)$ & 314 & $14(4.5)$ & 360 & $32(8.9)$ \\
\hline $\begin{array}{l}\text { Emergency department } \\
\text { setting }\end{array}$ & 367 & $41(11.1)$ & 94 & $12(12.8)$ & 153 & $16(10.5)$ & 120 & $13(10.8)$ \\
\hline \multicolumn{9}{|l|}{ Department } \\
\hline Internal medicine & 683 & $38(5.6)$ & 258 & $18(7.0)$ & 234 & $9(3.8)$ & 191 & $11(5.8)$ \\
\hline Urology & 116 & $22(19.0)$ & 35 & $8(22.9)$ & 25 & $0(0.0)$ & 56 & $14(25.0)$ \\
\hline Oral surgery & 139 & $19(13.7)$ & 29 & $3(3.4)$ & 0 & $0(0.0)$ & 110 & $16(14.5)$ \\
\hline Paediatrics & 135 & $19(14.1)$ & 7 & $0(0.0)$ & 68 & $4(5.9)$ & 60 & $15(25.0)$ \\
\hline Otolaryngology & 160 & $16(10.0)$ & 48 & $6(12.5)$ & 46 & $3(6.5)$ & 66 & $7(10.6)$ \\
\hline Dermatology & 117 & $15(12.8)$ & 23 & $3(13.0)$ & 25 & $1(4.0)$ & 69 & $11(15.9)$ \\
\hline Plastic surgery & 43 & $11(25.6)$ & 9 & $2(22.2)$ & 34 & $9(26.5)$ & 0 & NA \\
\hline Orthopaedics & 157 & $8(5.1)$ & 56 & $4(7.1)$ & 19 & $0(0.0)$ & 82 & $4(4.9)$ \\
\hline Neurosurgery & 67 & $5(7.5)$ & 10 & $0(0.0)$ & 30 & $2(6.7)$ & 27 & $3(11.1)$ \\
\hline Surgery & 129 & $4(3.1)$ & 42 & $0(0.0)$ & 48 & $3(6.3)$ & 39 & $1(25.6)$ \\
\hline \multicolumn{9}{|l|}{ Diagnosis } \\
\hline Common cold & 49 & $3(6.1)$ & 15 & $1(6.7)$ & 18 & $1(5.6)$ & 16 & $1(6.3)$ \\
\hline Wound & 39 & $17(43.6)$ & 8 & $2(25.0)$ & 17 & $10(58.8)$ & 14 & $5(35.7)$ \\
\hline Dental infection & 37 & $12(32.4)$ & 12 & $2(16.7)$ & 0 & NA & 25 & $10(40.0)$ \\
\hline Acute gastroenteritis & 27 & $1(3.7)$ & 8 & $0(0.0)$ & 11 & $1(9.1)$ & 8 & $0(0.0)$ \\
\hline Acute pharyngitis & 21 & $10(47.6)$ & 6 & $3(50.0)$ & 5 & $0(0.0)$ & 10 & $7(70.0)$ \\
\hline Acute bronchitis & 20 & $9(45.0)$ & 4 & $2(50.0)$ & 3 & $1(33.3)$ & 13 & $6(46.2)$ \\
\hline Urinary tract infection & 19 & $19(100.0)$ & 7 & $7(100.0)$ & 3 & $3(100.0)$ & 9 & $9(100.0)$ \\
\hline Fever unspecified & 17 & $1(5.9)$ & 6 & $1(16.7)$ & 1 & $0(0.0)$ & 10 & $0(0.0)$ \\
\hline Influenza & 16 & $11(68.8)$ & 3 & $2(66.7)$ & 6 & $3(50.0)$ & 7 & $6(85.7)$ \\
\hline Bacterial pneumonia & 14 & $12(85.7)$ & 4 & $3(75.0)$ & 4 & $3(75.0)$ & 6 & $6(100.0)$ \\
\hline Rhinitis & 13 & $0(0.0)$ & 2 & $0(0.0)$ & 1 & $0(0.0)$ & 10 & $0(0.0)$ \\
\hline Skin infection & 12 & $11(91.7)$ & 2 & $2(100.0)$ & 1 & $0(0.0)$ & 9 & $9(100.0)$ \\
\hline Exacerbation of asthma & 10 & $1(10.0)$ & 4 & $1(25.0)$ & 3 & $0(0.0)$ & 3 & $0(0.0)$ \\
\hline Cough unspecified & 6 & $0(0.0)$ & 2 & $0(0.0)$ & 1 & $0(0.0)$ & 3 & $0(0.0)$ \\
\hline Burn & 6 & $0(0.0)$ & 1 & $0(0.0)$ & 1 & $0(0.0)$ & 4 & $0(0.0)$ \\
\hline Genital infection & 5 & $4(80.0)$ & 1 & $1(100.0)$ & 1 & $0(0.0)$ & 3 & $3(100.0)$ \\
\hline Exacerbation of COPD & 4 & $1(25.0)$ & 1 & $0(0.0)$ & 2 & $0(0.0)$ & 1 & $1(100.0)$ \\
\hline Acute sinusitis & 4 & $2(50.0)$ & 2 & $1(50.0)$ & 1 & $0(0.0)$ & 1 & $1(100.0)$ \\
\hline Otitis externa & 3 & $0(0.0)$ & 0 & NA & 0 & NA & 3 & NA \\
\hline $\begin{array}{l}\text { Non-suppurative otitis } \\
\text { media }\end{array}$ & 3 & $0(0.0)$ & 1 & $0(0.0)$ & 2 & $0(0.0)$ & 0 & NA \\
\hline Acute otitis media & 3 & $2(66.7)$ & 0 & NA & 2 & $1(50.0)$ & 1 & $1(100.0)$ \\
\hline Acute prostatitis & 2 & $2(100.0)$ & 2 & $2(100.0)$ & 0 & NA & 0 & NA \\
\hline
\end{tabular}

Continued 
Table 2 Continued

\begin{tabular}{|c|c|c|c|c|c|c|c|c|}
\hline \multirow[b]{2}{*}{ Characteristics } & \multicolumn{2}{|c|}{ All $(n=1972)$} & \multicolumn{2}{|c|}{ Tokyo (n=637) } & \multicolumn{2}{|c|}{ Nagasaki $(n=608)$} & \multicolumn{2}{|c|}{ Tochigi (n=727) } \\
\hline & Total & $\begin{array}{l}\text { Visits with } \\
\text { antimicrobial } \\
\text { drugs }\end{array}$ & Total & $\begin{array}{l}\text { Visits with } \\
\text { antimicrobial } \\
\text { drugs }\end{array}$ & Total & $\begin{array}{l}\text { Visits with } \\
\text { antimicrobial } \\
\text { drugs }\end{array}$ & Total & $\begin{array}{l}\text { Visits with } \\
\text { antimicrobial } \\
\text { drugs }\end{array}$ \\
\hline Acne & 2 & $1(50.0)$ & 0 & NA & 1 & $0(0.0)$ & 1 & $1(100.0)$ \\
\hline
\end{tabular}

*Values are expressed as the number and the percentage of the total number unless otherwise stated.

COPD, chronic obstructive pulmonary disease; NA, not applicable.

prescribed in ambulatory settings were used for prophylaxis. Therefore, the prevalence of prophylactic use of antimicrobial drugs in this study seems high. However, our findings may support that $20 \%-40 \%$ of antimicrobial drugs prescribed in the ambulatory setting could not be linked to diagnostic codes for infectious diseases in recent studies ${ }^{9} 1021$ investigating antimicrobial drug use because antimicrobial drugs used for prophylaxis were not considered in these studies. ${ }^{9102021}$ Further studies are needed to investigate the prevalence and appropriateness of antimicrobial drug use for prophylaxis in ambulatory settings.
Types and prescribers of antimicrobial drugs

Our findings are consistent with those in past studies $^{21}{ }^{22}$ outside Japan that reported penicillin was the most frequently used antimicrobial drug, although thirdgeneration cephalosporins were more frequently used in the present study than in past studies. ${ }^{21} 22$ However, our finding is not consistent with those of recent Japanese studies $^{2023}$ reporting that penicillin was not included in the top three most frequently used antimicrobial drugs. These Japanese studies, unlike our study, used data collected before the launch of the Japanese national

Table 3 Types of the 162 antimicrobial drugs prescribed at ambulatory visits*

\begin{tabular}{|c|c|c|c|c|}
\hline Type & $\begin{array}{l}\text { All } \\
(n=162)\end{array}$ & $\begin{array}{l}\text { Tokyo } \\
(\mathrm{n}=46)\end{array}$ & $\begin{array}{l}\text { Nagasaki } \\
(n=34)\end{array}$ & $\begin{array}{l}\text { Tochigi } \\
(\mathrm{n}=82)\end{array}$ \\
\hline Penicillins & $48(29.6)$ & $8(17.4)$ & $11(32.4)$ & $29(35.4)$ \\
\hline Amoxicillin & $28(17.3)$ & $4(8.7)$ & $4(11.8)$ & $20(24.4)$ \\
\hline Amoxicillin-clavulanate & $19(11.7)$ & $4(8.7)$ & $7(20.6)$ & $8(9.8)$ \\
\hline Ampicillin-sulbactam & $1(0.6)$ & $0(0.0)$ & $0(0.0)$ & $1(1.2)$ \\
\hline Third-generation cephalosporins & $35(21.6)$ & $7(15.2)$ & $6(17.6)$ & $22(26.8)$ \\
\hline Cefcapene pivoxil & $18(11.1)$ & $2(4.3)$ & $4(11.8)$ & 12 (14.6) \\
\hline Cefditoren pivoxil & $10(6.2)$ & $0(0.0)$ & $0(0.0)$ & $10(12.2)$ \\
\hline Ceftriaxone & $4(2.5)$ & $4(8.7)$ & $0(0.0)$ & $0(0.0)$ \\
\hline Cefdinir & $3(1.9)$ & $1(2.2)$ & $2(5.9)$ & $0(0.0)$ \\
\hline Quinolones & $20(12.4)$ & $11(23.9)$ & $5(14.7)$ & $4(4.9)$ \\
\hline Levofloxacin & $15(9.3)$ & $9(19.6)$ & $3(8.8)$ & $3(3.7)$ \\
\hline Garenoxacin & $4(2.5)$ & $2(4.3)$ & $2(5.9)$ & $0(0.0)$ \\
\hline Sitafloxacin & $1(0.6)$ & $0(0.0)$ & $0(0.0)$ & $1(1.2)$ \\
\hline Macrolides & $18(11.1)$ & $5(10.9)$ & $0(0.0)$ & $13(15.9)$ \\
\hline Clarithromycin & $9(5.6)$ & $3(6.5)$ & $0(0.0)$ & $6(7.3)$ \\
\hline Azithromycin & $5(3.1)$ & $2(4.3)$ & $0(0.0)$ & $3(3.7)$ \\
\hline Roxithromycin & $4(2.5)$ & $0(0.0)$ & $0(0.0)$ & $4(4.9)$ \\
\hline Antivirals & $15(9.3)$ & $4(8.7)$ & $4(11.8)$ & $7(8.5)$ \\
\hline Oseltamivir & $10(6.2)$ & $3(6.5)$ & $1(2.9)$ & $6(7.3)$ \\
\hline Valacyclovir & $3(1.9)$ & $1(2.2)$ & $1(2.9)$ & $1(1.2)$ \\
\hline Laninamivir & $2(1.2)$ & $0(0.0)$ & $2(5.9)$ & $0(0.0)$ \\
\hline Others & $10(6.2)$ & $4(8.7)$ & $1(2.9)$ & $5(6.1)$ \\
\hline
\end{tabular}

*Values are the number of antimicrobial drugs, with the percentage of the total number of antimicrobial drugs in parentheses according to the site. 
Table 4 The reasons for antimicrobial use by survey site*

\begin{tabular}{|c|c|c|c|c|}
\hline Reasons & $\begin{array}{l}\text { Total } \\
(n=162)\end{array}$ & $\begin{array}{l}\text { Tokyo } \\
(n=46)\end{array}$ & $\begin{array}{l}\text { Nagasaki } \\
(n=34)\end{array}$ & $\begin{array}{l}\text { Tochigi } \\
(\mathrm{n}=82)\end{array}$ \\
\hline Treatment & $125(77.2)$ & $35(76.1)$ & 19 (55.9) & $71(86.6)$ \\
\hline \multicolumn{5}{|l|}{ Prophylaxis } \\
\hline Surgical prophylaxis & $11(6.8)$ & $4(8.7)$ & $3(8.8)$ & $4(4.9)$ \\
\hline Wound prophylaxis & $18(11.1)$ & $2(4.3)$ & $10(29.4)$ & $6(7.3)$ \\
\hline Unknown reasons & $3(1.9)$ & $1(2.2)$ & $2(5.9)$ & $0(0.0)$ \\
\hline
\end{tabular}

*Values are the number of antimicrobial drugs, with the percentage of the total number of antimicrobial drugs in parentheses according to the site.

action plan to combat antimicrobial-resistant bacteria. ${ }^{6}$ Therefore, the types of antimicrobial drugs used in the ambulatory setting might have changed in Japan since the launch of the Japanese national action plan. Further studies are needed to investigate antimicrobial drug use in ambulatory settings in Japan considering recent data.

In the present study, $11.7 \%$ of all antimicrobial drugs were prescribed by dentists. Our finding is consistent with that of a past study reporting that $10 \%$ of all outpatient antibiotics were prescribed by dentists. ${ }^{22}$ Moreover, half of the antimicrobial drugs used for dental infections in the present study were judged to be unnecessary. This result is consistent with those of past studies conducted in the $\mathrm{UK}^{24}{ }^{25}$ showing that inappropriate antimicrobial drug use

Table 5 The evidence for infectious disease diagnoses and indications for antimicrobial therapy*

\begin{tabular}{lcll}
\hline & Total & $\begin{array}{l}\text { Insufficient } \\
\text { evidence for } \\
\text { diagnosis }\end{array}$ & $\begin{array}{l}\text { No } \\
\text { indication for } \\
\text { antimicrobial } \\
\text { drugs }\end{array}$ \\
\hline Diagnosist & 125 & $45(36.0)$ & $60(48.0)$ \\
\hline $\begin{array}{l}\text { Any } \\
\text { infection }\end{array}$ & 20 & $8(40.0)$ & $8(40.0)$ \\
$\begin{array}{l}\text { Bacterial } \\
\text { pneumonia }\end{array}$ & 13 & $3(23.1)$ & $3(23.1)$ \\
\hline $\begin{array}{l}\text { Acute pharyngitis } \\
\text { Skin infection }\end{array}$ & 11 & $5(45.5)$ & $9(81.8)$ \\
\hline $\begin{array}{l}\text { Influenza } \\
\text { Dental infection }\end{array}$ & 11 & $1(9.1)$ & $1(9.1)$ \\
\hline Acute bronchitis & 9 & $0(0.0)$ & $1(9.1)$ \\
\hline $\begin{array}{l}\text { Common cold } \\
\text { Varicella zoster }\end{array}$ & 3 & $3(20.0)$ & $5(50.0)$ \\
\hline Gastroenteritis & 3 & $1(33.3)$ & $9(100.0)$ \\
\hline
\end{tabular}

*Values are the numbers of antimicrobial drugs, with the percentages of the total numbers of antimicrobial drugs in parentheses according to the site.

†Only infectious diseases accounting for more than $2 \%$ of all cases treated by antimicrobial drugs. by dentists was common. However, it is uncertain whether our results could be compared with those of these past studies because dentists in the UK generally do not practise in hospital settings, unlike in Japan. Given that a substantial proportion of antimicrobial drugs are prescribed by dentists, monitoring and improving the appropriateness of antimicrobial drug use by dentists ${ }^{26}$ are important to reduce the inappropriate use of outpatient antimicrobial drugs.

\section{Proportion of antimicrobial therapy according to infectious diseases}

The proportions of antimicrobial therapy for the common cold, acute gastroenteritis, acute pharyngitis and acute bronchitis in the present study were much lower than those in recent studies that analysed data before 2015. 202327 It is possible that the Japanese national action plan launched in 2016 might contribute to this reduction in unnecessary antimicrobial use. Our findings also indirectly support the latest Nippon Antimicrobial Resistance One Health Reports, ${ }^{28}$ which indicate that the volume of oral antimicrobial drug use in Japan has gradually declined since 2017, although this report did not investigate the indications of antimicrobial drug use. Further studies are needed to investigate antimicrobial drug use in ambulatory settings considering recent data.

In the present study, antimicrobial drugs were prescribed for nearly all patients who were diagnosed with UTI and pneumonia. However, although antimicrobial drugs are needed in almost all cases of UTI and pneumonia, the proportion of antimicrobial therapy for patients with UTI and pneumonia was $60 \%-80 \%$ in recent studies 8202329 in which antimicrobial drugs were linked to infectious diseases according to the ICD codes. A recent study ${ }^{12}$ reported that ICD diagnostic codes had limited predictive value for validated cases of cystitis and pneumonia. Our findings implicate that the method to audit the use of outpatient antimicrobial drugs by using ICD codes needs to be improved.

\section{Appropriateness of antimicrobial therapy}

The proportion of antimicrobial drugs that were unnecessary in the present study was higher than that in recent 
studies conducted outside $\mathrm{Japan}^{8-10}$ but is similar to that in a recent Japanese study. ${ }^{23}$ Even though the proportion of antimicrobial therapy for infectious diseases that generally do not require the use of antimicrobial drugs was lower in the present study than in recent studies, ${ }^{8-10} 23$ the rate of unnecessary antimicrobial drugs in the present study still seems high. However, unlike other studies, ${ }^{8-10} 23$ we investigated the evidence for physicians' diagnoses of infectious diseases in addition to evaluating whether antimicrobial drugs were prescribed for infectious diseases that required antimicrobial therapy. Diagnoses in approximately one-third of infectious disease cases treated by antimicrobial drugs in this study did not have sufficient evidence. For example, UTI generally requires antimicrobial therapy in all cases. However, $40 \%$ of cases treated as UTIs with antimicrobial drugs in this study did not have sufficient evidence for UTI. Therefore, antimicrobial drugs for these UTI cases without diagnostic evidence were judged to be unnecessary. Thus, cases without sufficient evidence of the presence of infectious diseases might have increased the rate of unnecessary antimicrobial drug prescription in the present study compared with other studies $^{8-1023}$ in which the diagnostic evidence of infectious diseases was not assessed. Our findings support the results of previous studies reporting that physicians' diagnoses of infectious diseases were sometimes inaccurate, particularly for UTI and pneumonia. ${ }^{11}{ }^{12}$ Further efforts to increase the accuracy of physicians' diagnoses for infectious diseases and reduce the inappropriate use of antimicrobial drugs are needed.

In the present study, more than half of the antimicrobial drugs used for wound or surgical prophylaxis were prescribed for more than 2 days. This result is problematic because antimicrobial prophylaxis is not indicated, or a single dose of antimicrobial drugs for prophylaxis is sufficient for most types of ambulatory surgical procedures and wound care. ${ }^{30}$ Further efforts to reduce unnecessary antimicrobial prophylaxis for ambulatory surgical procedures and wound care are needed.

\section{Variations of antimicrobial drug use among the investigated hospitals}

Although the aim of our study was not to determine the difference in antimicrobial drug use among Japanese hospitals, several points regarding variations of antimicrobial drug use among the investigated hospitals in the present study need to be mentioned. First, the prevalence of antimicrobial drug use in NHO Tochigi Medical Center was approximately twice that of the other two hospitals. In particular, the differences in antimicrobial drug use for the paediatric and urological departments among the three hospitals are notable. Second, the proportion of quinolone use among prescribed antimicrobial drugs was much higher in NHO Tokyo Medical Center than in the other two hospitals. Although the reason for this variation remains uncertain in the present study, our results are similar to those of past studies ${ }^{1923}$ reporting variations in antimicrobial drug prescription. Further studies are needed to investigate the factors that contribute to the variation in antimicrobial drug prescription among Japanese hospitals.

\section{Implications for clinical practice}

Three-fourths of the antimicrobial drugs prescribed in the ambulatory setting are used for infection treatment, but approximately half of those drugs may be unnecessary. Therefore, further efforts to reduce unnecessary antimicrobial drug use are needed. Furthermore, approximately one-fifth of outpatient antimicrobial drugs may be prescribed for prophylactic use. Therefore, investigations into the appropriateness of prophylactic antimicrobial drug use are also warranted in the future. A national action plan for antimicrobial resistance (AMR) needs to focus more on prophylactic antimicrobial drug use.

Finally, most past studies on outpatient antimicrobial use have focused on the misuse of antimicrobial drugs for infectious diseases, such as the common cold, which are not indications for antimicrobial therapy in most cases. Little attention has been paid to problems in the diagnostic accuracy for infectious diseases, such as for pneumonia and UTIs, which are indications for antimicrobial therapy. In fact, a Japanese national action plan for AMR scarcely mentions these problems in diagnostic accuracy. ${ }^{6}$ Even a recent published revised manual of antimicrobial stewardship in Japan only mentions the infectious diseases that are not indications for antimicrobial therapy in most cases. ${ }^{32}$ Given the inaccuracy of physicians' diagnoses and diagnostic codes for infectious diseases treated by antimicrobial drugs, the monitoring of the accuracy of physicians' diagnoses and diagnostic codes is critical for assessing the appropriateness of antimicrobial drug use. Therefore, a national AMR action plan needs to focus more on the accuracy of the diagnosis of infectious diseases. It might be difficult to implement the periodic administration of a survey such as the one used in this study at the national level because it is labour intensive. Moreover, given that electronic medical records are used in less than $50 \%$ of the hospitals and clinics in Japan, ${ }^{33}$ a more labour-intensive survey relying on paper medical records would be needed in the majority of healthcare facilities. However, the annual administration of a shorter survey at the national level seems feasible, at least in healthcare facilities that use electronic medical records. Further investigations of the feasibility and sustainability of a survey based on chart review to assess outpatient antimicrobial drug use at the national level are warranted. To address AMR, monitoring the appropriateness of both the diagnosis and the indication for antimicrobial therapy with regard to infectious diseases is needed.

\section{Strength and weakness}

This was the first prospective, multicentre study to investigate the prevalence and appropriateness of outpatient antimicrobial drug use in Japan since the national action plan was launched in 2016. Moreover, our study was the first to evaluate the proportion of prophylactic 
antimicrobial drug use among all outpatient antimicrobial drug use. The indications for and appropriateness of antimicrobial drugs were investigated by using a chart review rather than diagnostic codes. Therefore, the rationale for nearly all antimicrobial drugs was known. In addition, evidence for the diagnosis of infectious disease treated by antimicrobial drugs was also investigated. This investigation avoided the challenges of inaccurate physicians' diagnoses ${ }^{11}$ and diagnostic shifting. ${ }^{12}$

Several limitations need to be mentioned. First, only three hospitals were included in this study. Moreover, no physicians' offices providing mainly primary care in Japan were included. Therefore, the generalisability of our results might be limited. Second, we did not contact the physicians who prescribed the antimicrobial drugs. Therefore, retrieved information regarding the reasons for antimicrobial drug prescription and ambulatory diagnoses might be inaccurate. Moreover, the ambulatory diagnosis might not reflect the final accurate diagnosis because data were retrieved from medical notes from only the first visit. Fourth, screening logs were not obtained. Therefore, selection bias in the present study is difficult to assess. Fifth, interobserver agreement regarding information on antimicrobial drug prescribing and diagnosis was not investigated, although past studies reported that interobserver agreement regarding information on antimicrobial drug prescribing and diagnosis was good. ${ }^{34} 35$ Sixth, our survey investigated only winter days. Given the seasonal variation in the occurrence of infectious diseases, our results might not reflect practices throughout the year. Moreover, only 4 days were investigated for one of the three hospitals included in the present study. Therefore, a difference in practice due to day of week might also affect the results. In addition, the outbreak of COVID-19 might affect our outcomes, although it is probable that the study period did not overlap with this outbreak in Japan. Seventh, we did not investigate factors other than the indication of antimicrobial drugs, such as their dose and spectrum, when determining the appropriateness of antimicrobial therapy. Moreover, we did not evaluate the appropriateness of antimicrobial drugs used for the reasons other than treatment. Therefore, the assessment of appropriateness of ambulatory antimicrobial drug use may be insufficient. Eighth, we excluded visits for annual health checks and scheduled visits. Therefore, visits of patients recently discharged from the hospital who were using antimicrobial drugs were missed. Ninth, given the possibility that antimicrobial drug prescription habits are different among the investigated hospitals, the sample size per hospital should be determined based on the size of the hospitals. Finally, we excluded topical antimicrobial drugs. Therefore, our results underestimated the prevalence of ambulatory antimicrobial use.

\section{CONCLUSIONS}

One in every 13 ambulatory visits results in an antimicrobial prescription in Japan. Three-fourths of the prescribed antimicrobial drugs are used for infection treatment, but approximately half of those drugs may be unnecessary. Further efforts to reduce unnecessary antimicrobial drug use are needed.

Acknowledgements We thank the reviewers of BMJ Open for their valuable comments, which improved the quality of this manuscript.

Contributors JK conceived this study. JK, MK and TM designed and wrote the protocol for this study. JK, MK and TM collected the data. JK analysed and guaranteed the data. JK wrote the draft of the manuscript. All authors contributed to the revision of the manuscript and read and approved the final manuscript.

Funding The authors have not declared a specific grant for this research from any funding agency in the public, commercial or not-for-profit sectors.

\section{Competing interests None declared.}

Patient and public involvement Patients and/or the public were not involved in the design, or conduct, or reporting, or dissemination plans of this research.

\section{Patient consent for publication Not required.}

Ethics approval The protocol for this study was approved by the Medical Ethics Committee of the National Hospital Organization Tochigi Medical Center (No 2019-18), the National Hospital Organization Tokyo Medical Center (No R19-137) and the National Hospital Organization Nagasaki Medical Center (No 2019119). This research was conducted in accordance with the Ethics Guidelines for Epidemiological Research in Japan and was carried out in accordance with the principles of the Declaration of Helsinki. The need to obtain individual informed consent was formally waived by the Medical Ethics Committee of each institution because deidentified data were collected without contacting the patients. However, as per the Japanese Ethics Guidelines, we displayed an opt-out statement in the waiting room and on the web page of the hospital to inform the patients of the study and provide them with the opportunity to refuse to permit the use of their data.

Provenance and peer review Not commissioned; externally peer reviewed.

Data availability statement All data relevant to the study are included in the article or uploaded as supplementary information. No additional data.

Open access This is an open access article distributed in accordance with the Creative Commons Attribution Non Commercial (CC BY-NC 4.0) license, which permits others to distribute, remix, adapt, build upon this work non-commercially, and license their derivative works on different terms, provided the original work is properly cited, appropriate credit is given, any changes made indicated, and the use is non-commercial. See: http://creativecommons.org/licenses/by-nc/4.0/.

ORCID iD

Junpei Komagamine http://orcid.org/0000-0002-5899-4760

\section{REFERENCES}

1 Ammerlaan HSM, Harbarth S, Buiting AGM, et al. Secular trends in nosocomial bloodstream infections: antibiotic-resistant bacteria increase the total burden of infection. Clin Infect Dis 2013;56:798-805.

2 Cosgrove SE. The relationship between antimicrobial resistance and patient outcomes: mortality, length of hospital stay, and health care costs. Clin Infect Dis 2006;42 Suppl 2:S82-9.

3 de Kraker MEA, Wolkewitz M, Davey PG, et al. Clinical impact of antimicrobial resistance in European hospitals: excess mortality and length of hospital stay related to methicillin-resistant Staphylococcus aureus bloodstream infections. Antimicrob Agents Chemother 2011;55:1598-605.

4 Chatterjee A, Modarai M, Naylor NR, et al. Quantifying drivers of antibiotic resistance in humans: a systematic review. Lancet Infect Dis 2018;18:e368-78.

5 World Health Organization. Global action plan on antimicrobial resistance. Available: https://www.who.int/antimicrobial-resistance/ global-action-plan/en/ [Accessed 31 Mar 2020].

6 The Government of Japan. National action plan on antimicrobial resistance (AMR) 2016-2020. Available: https://www.mhlw.go.jp/file/ 06-Seisakujouhou-10900000-Kenkoukyoku/0000138942 [Accessed 28 Mar 2020].

7 Public Health England. English surveillance programme for antimicrobial utilization and resistance (ESPAUR). Report 2018-2019. 
Available: https://assets.publishing.service.gov.uk/government/ uploads/system/uploads/attachment_data/file/843129/English_ Surveillance_Programme_for_Antimicrobial_Utilisation_and Resistance_2019.pdf [Accessed 31 Mar 2020].

8 Fleming-Dutra KE, Hersh AL, Shapiro DJ, et al. Prevalence of inappropriate antibiotic prescriptions among US ambulatory care visits, 2010-2011. JAMA 2016;315:1864-73.

9 Olesen SW, Barnett ML, MacFadden DR, et al. Trends in outpatient antibiotic use and prescribing practice among US older adults, 2011 15: observational study. BMJ 2018;362:k3155.

10 Chua K-P, Fischer MA, Linder JA. Appropriateness of outpatient antibiotic prescribing among privately insured us patients: ICD-10CM based cross sectional study. BMJ 2019;364:k5092.

11 Filice GA, Drekonja DM, Thurn JR, et al. Diagnostic errors that lead to inappropriate antimicrobial use. Infect Control Hosp Epidemiol 2015;36:949-56.

12 Livorsi DJ, Linn CM, Alexander B, et al. The value of electronically extracted data for auditing outpatient antimicrobial prescribing. Infect Control Hosp Epidemiol 2018;39:64-70.

13 Miliani K, L'Hériteau F, Astagneau P, et al. Non-Compliance with recommendations for the practice of antibiotic prophylaxis and risk of surgical site infection: results of a multilevel analysis from the INCISO surveillance network. J Antimicrob Chemother 2009;64:1307-15.

14 Kato D, Ryu H, Matsumoto T, et al. Building primary care in Japan: literature review. J Gen Fam Med 2019;20:170-9.

15 Ministry of Health, Labor and Welfare. Health statistics in Japan, 2010. Available: https://www.mhlw.go.jp/toukei/saikin/hw/hoken/ national/dl/22-00.pdf [Accessed 6 Jun 2020].

16 Magill SS, Edwards JR, Beldavs ZG, et al. Prevalence of antimicrobial use in US acute care hospitals, May-September 2011. JAMA2014;312:1438-46.

17 Harris AM, Hicks LA, Qaseem A, et al. Appropriate antibiotic use for acute respiratory tract infection in adults: advice for high-value care from the American College of physicians and the centers for disease control and prevention. Ann Intern Med 2016;164:425-34.

18 Infectious diseases Society of America. IDSA practice guidelines. Available: https://www.idsociety.org/practice-guideline/practiceguidelines/\#/name_na_str/ASC/0/+/ [Accessed 22 Mar 2019].

19 Shapiro DJ, Hicks LA, Pavia AT, et al. Antibiotic prescribing for adults in ambulatory care in the USA, 2007-09. J Antimicrob Chemother 2014;69:234-40.

20 Hashimoto $\mathrm{H}$, Matsui $\mathrm{H}$, Sasabuchi $\mathrm{Y}$, et al. Antibiotic prescription among outpatients in a Prefecture of Japan, 2012-2013: a retrospective claims database study. BMJ Open 2019;9:e026251.

21 Dolk FCK, Pouwels KB, Smith DRM, et al. Antibiotics in primary care in England: which antibiotics are prescribed and for which conditions? J Antimicrob Chemother 2018;73:ii2-10.
22 Hicks LA, Bartoces MG, Roberts RM, et al. Us outpatient antibiotic prescribing variation according to geography, patient population, and provider specialty in 2011. Clin Infect Dis 2015;60:1308-16.

23 Hashimoto H, Saito M, Sato J, et al. Indications and classes of outpatient antibiotic prescriptions in Japan: a descriptive study using the National database of electronic health insurance claims, 20122015. Int J Infect Dis 2020;91:1-8.

24 Cope AL, Barnes E, Howells EP, et al. Antimicrobial prescribing by dentists in Wales, UK: findings of the first cycle of a clinical audit. $\mathrm{Br}$ Dent J 2016;221:25-30.

25 Chate RAC, White S, Hale LRO, et al. The impact of clinical audit on antibiotic prescribing in general dental practice. Br Dent $J$ 2006;201:635-41.

26 Lockhart PB, Tampi MP, Abt E, et al. Evidence-Based clinical practice guideline on antibiotic use for the urgent management of pulpal- and periapical-related dental pain and intraoral swelling: a report from the American dental association. J Am Dent Assoc 2019;150:906-21.

27 Pouwels KB, Dolk FCK, Smith DRM, et al. Actual versus 'ideal' antibiotic prescribing for common conditions in English primary care. $J$ Antimicrob Chemother 2018;73:19-26.

28 One Health. Nippon AMR one health report (NAOR) [in Japanese], 2019. Available: https://www.mhlw.go.jp/content/10900000/ 000571551.pdf [Accessed 11 Jun 2020].

29 Palms DL, Hicks LA, Bartoces M, et al. Comparison of antibiotic prescribing in retail clinics, urgent care centers, emergency departments, and traditional ambulatory care settings in the United States. JAMA Intern Med 2018;178:1267-70.

30 Bratzler DW, Dellinger EP, Olsen KM, et al. Clinical practice guidelines for antimicrobial prophylaxis in surgery. Am J Health Syst Pharm 2013;70:195-283.

31 Cummings P, Del Beccaro MA. Antibiotics to prevent infection of simple wounds: a meta-analysis of randomized studies. Am J Emerg Med 1995;13:396-400.

32 Ministry of Health, Labor and Welfare. Manual of antimicrobial stewardship [in Japanese]. 2nd edition, 2020. https://www.mhlw.go. jp/content/10900000/000573655.pdf

33 Ministry of Health, Labor and Welfare. Current status of computerization in the medical field [in Japanese]. Available: https:// www.mhlw.go.jp/stf/seisakunitsuite/bunya/kenkou_iryou/iryou/ johoka/index.html [Accessed 26 Jul 2020].

34 Linder JA, Bates DW, Williams DH, et al. Acute infections in primary care: accuracy of electronic diagnoses and electronic antibiotic prescribing. J Am Med Inform Assoc 2006;13:61-6.

35 Cadieux G, Tamblyn R. Accuracy of physician billing claims for identifying acute respiratory infections in primary care. Health Serv Res 2008;43:2223-38. 